\title{
Total Synthesis of Cochleamycin A
}

Thomas A. Dineen and William R. Roush*

Department of Chemistry, University of Michigan, Ann Arbor, MI, 48109

Email: roush@umich.edu

Supporting Information Part II - NMR Spectra 


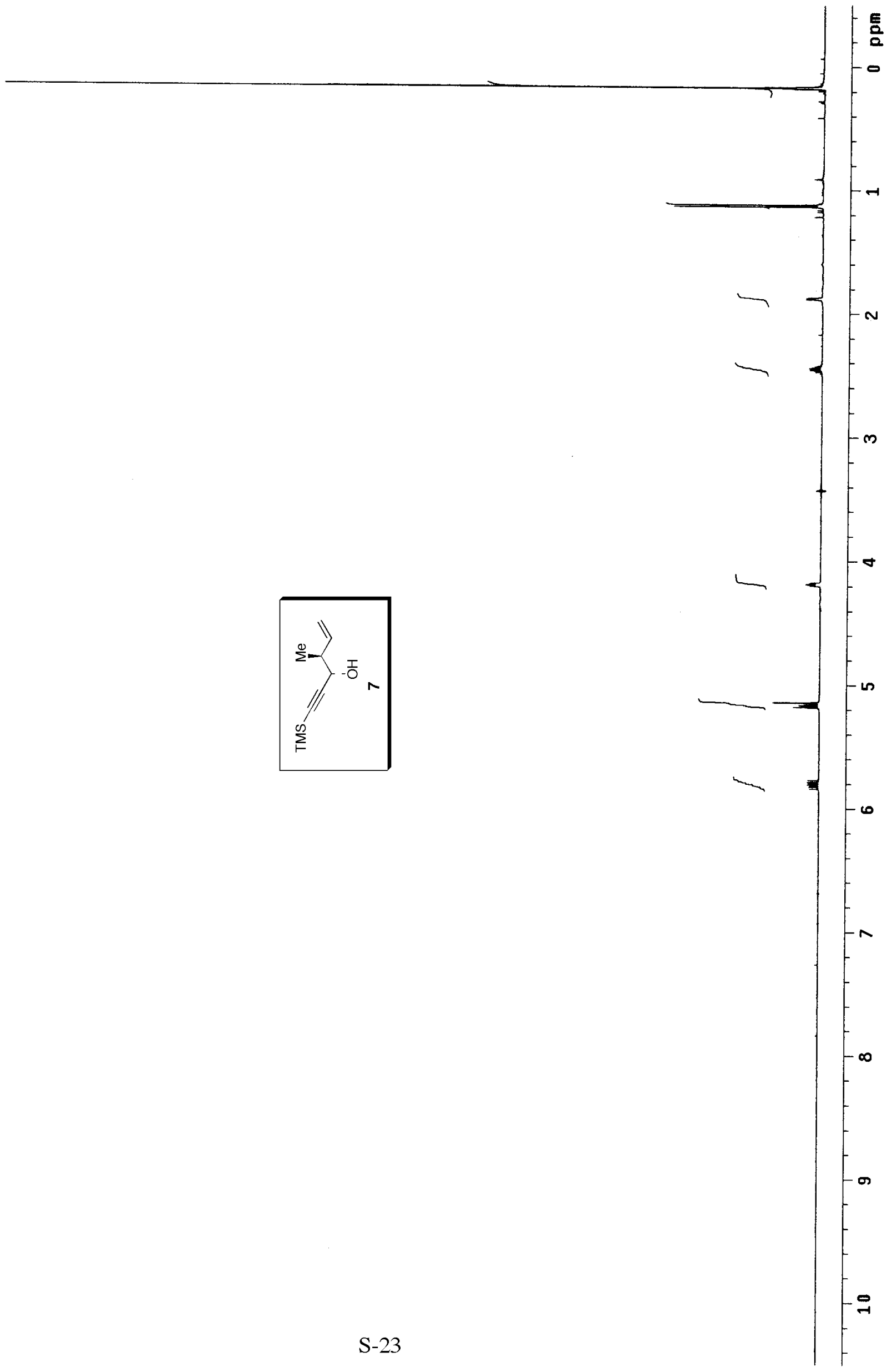




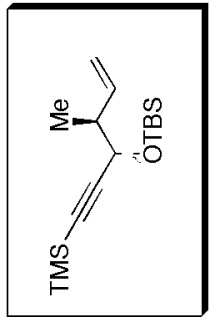




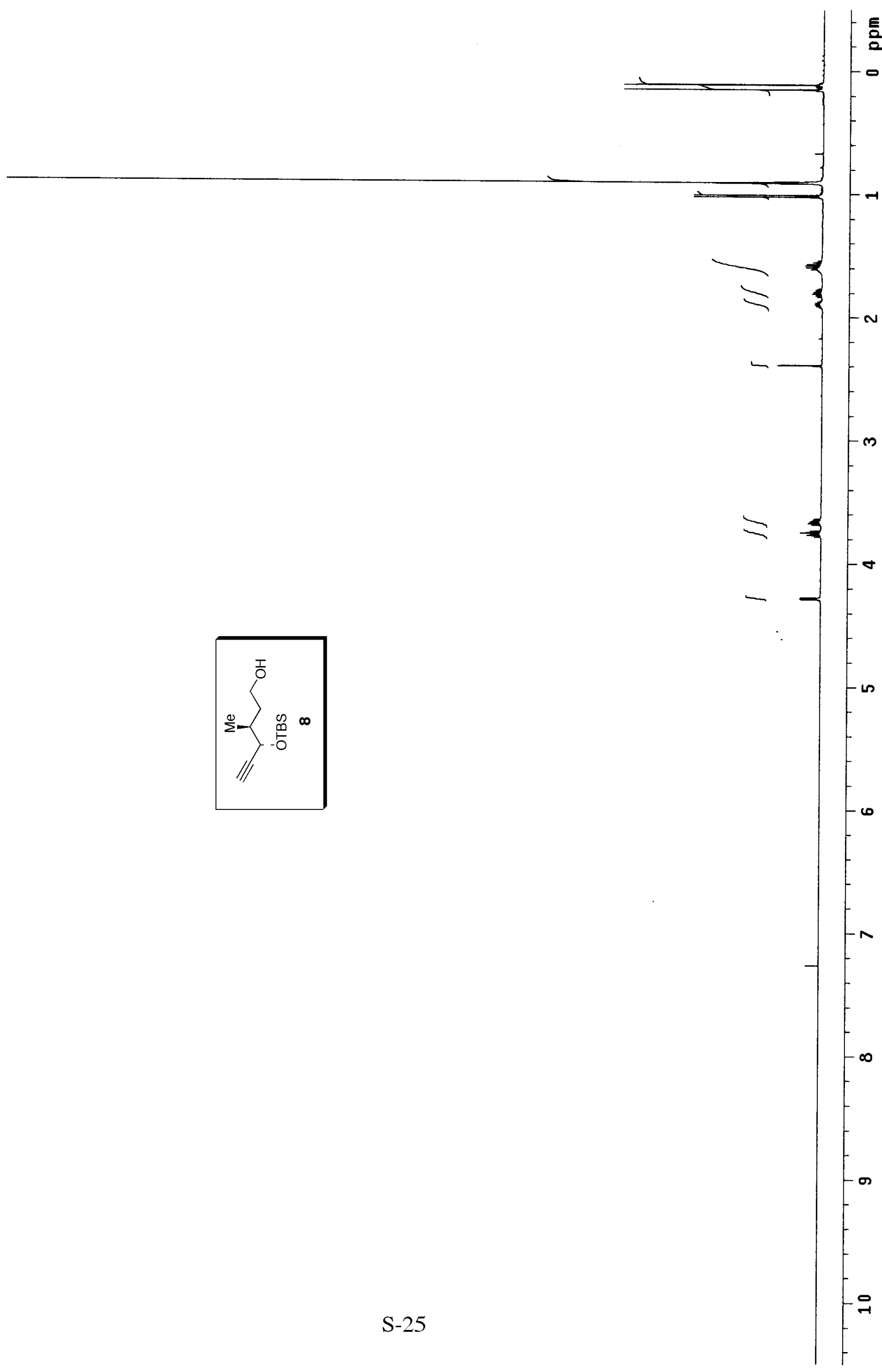




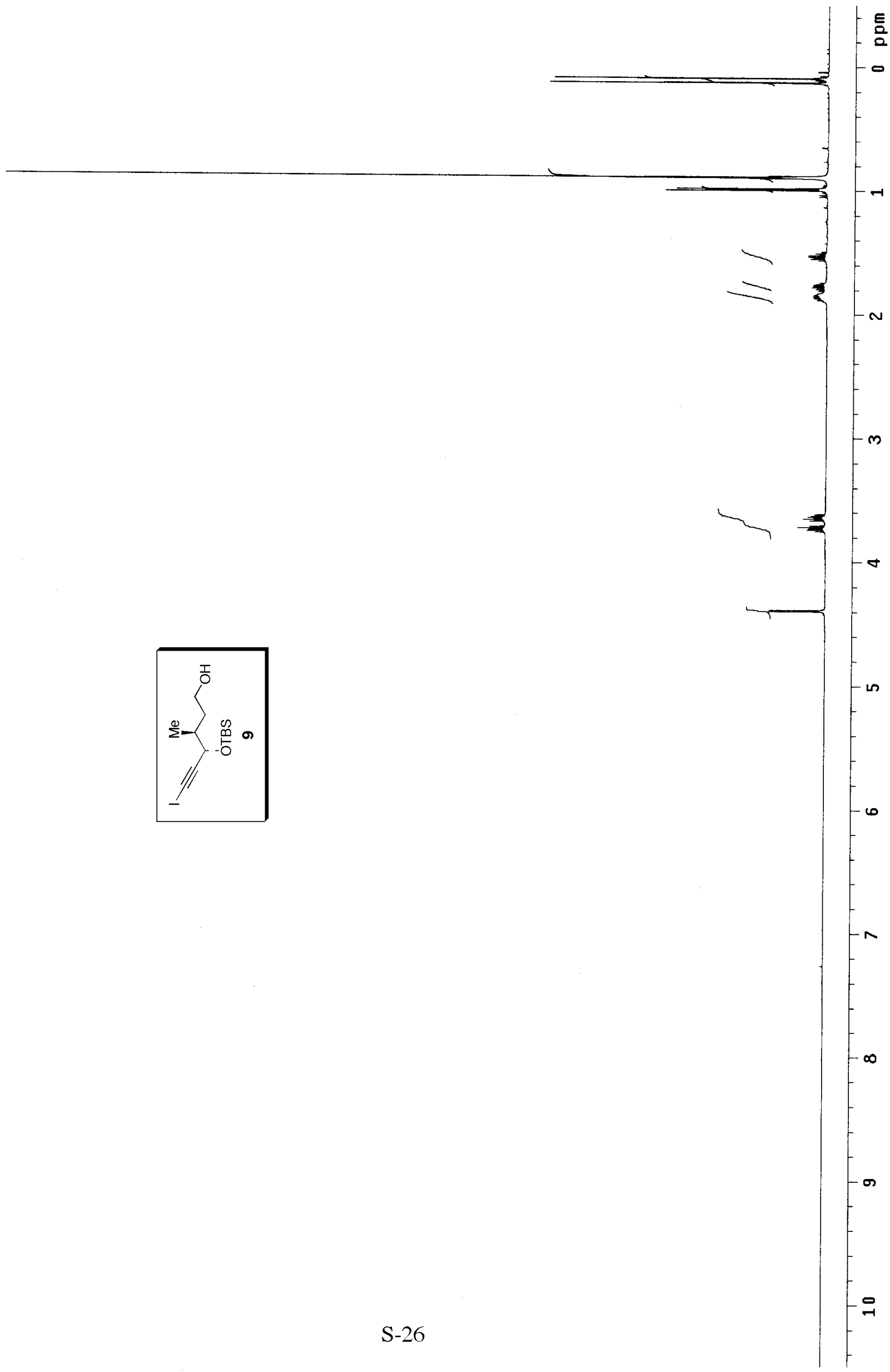




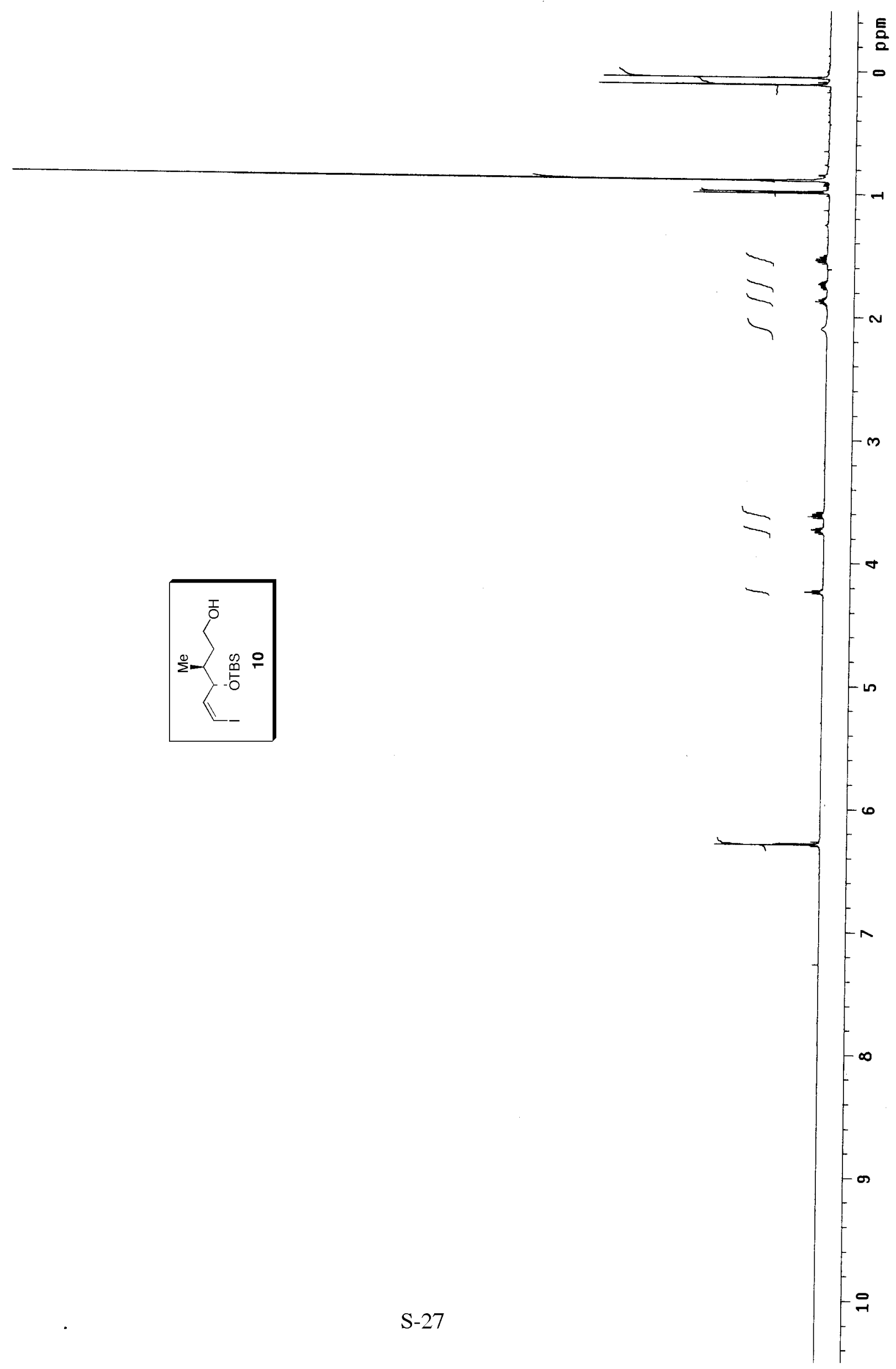




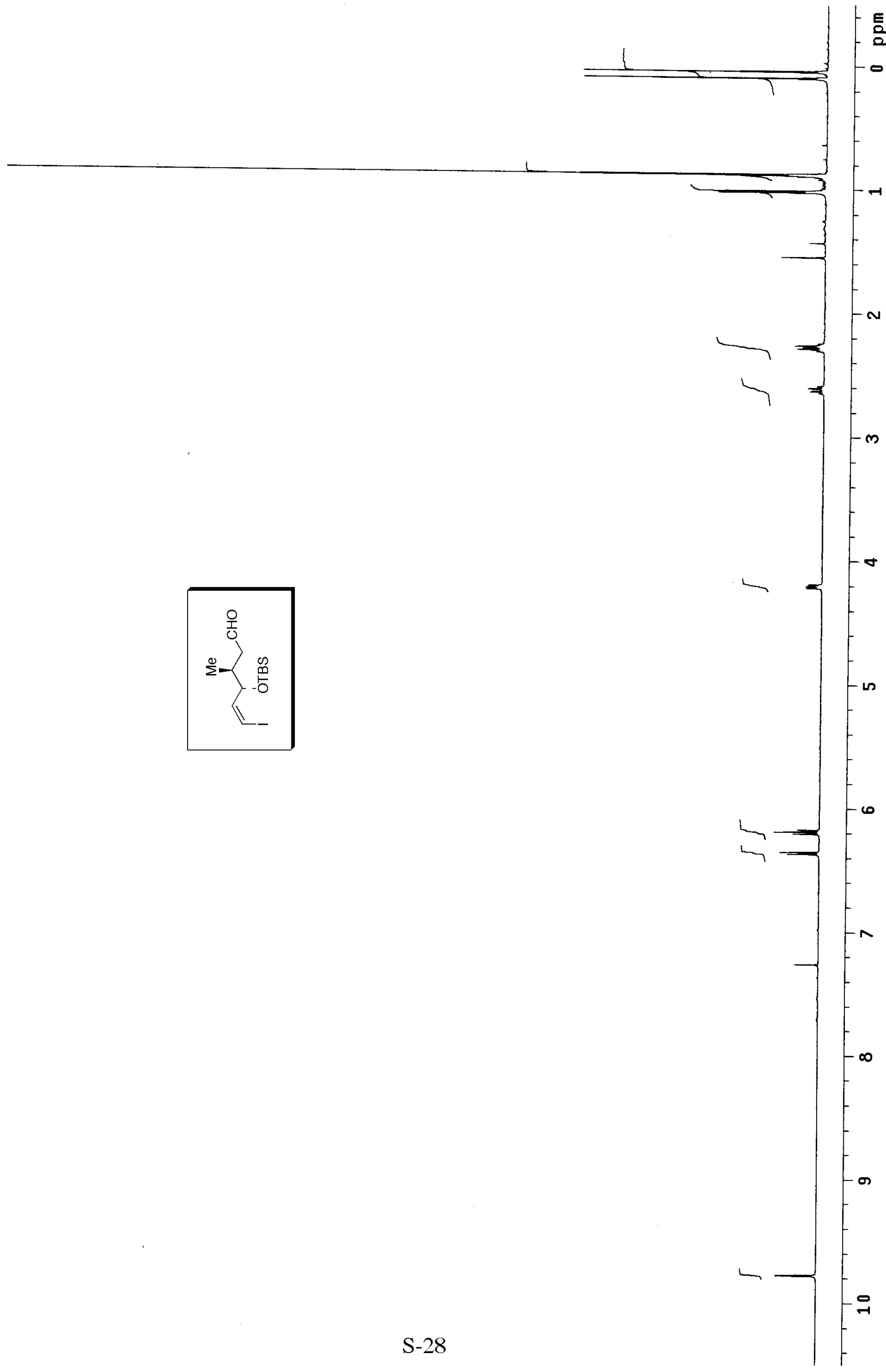




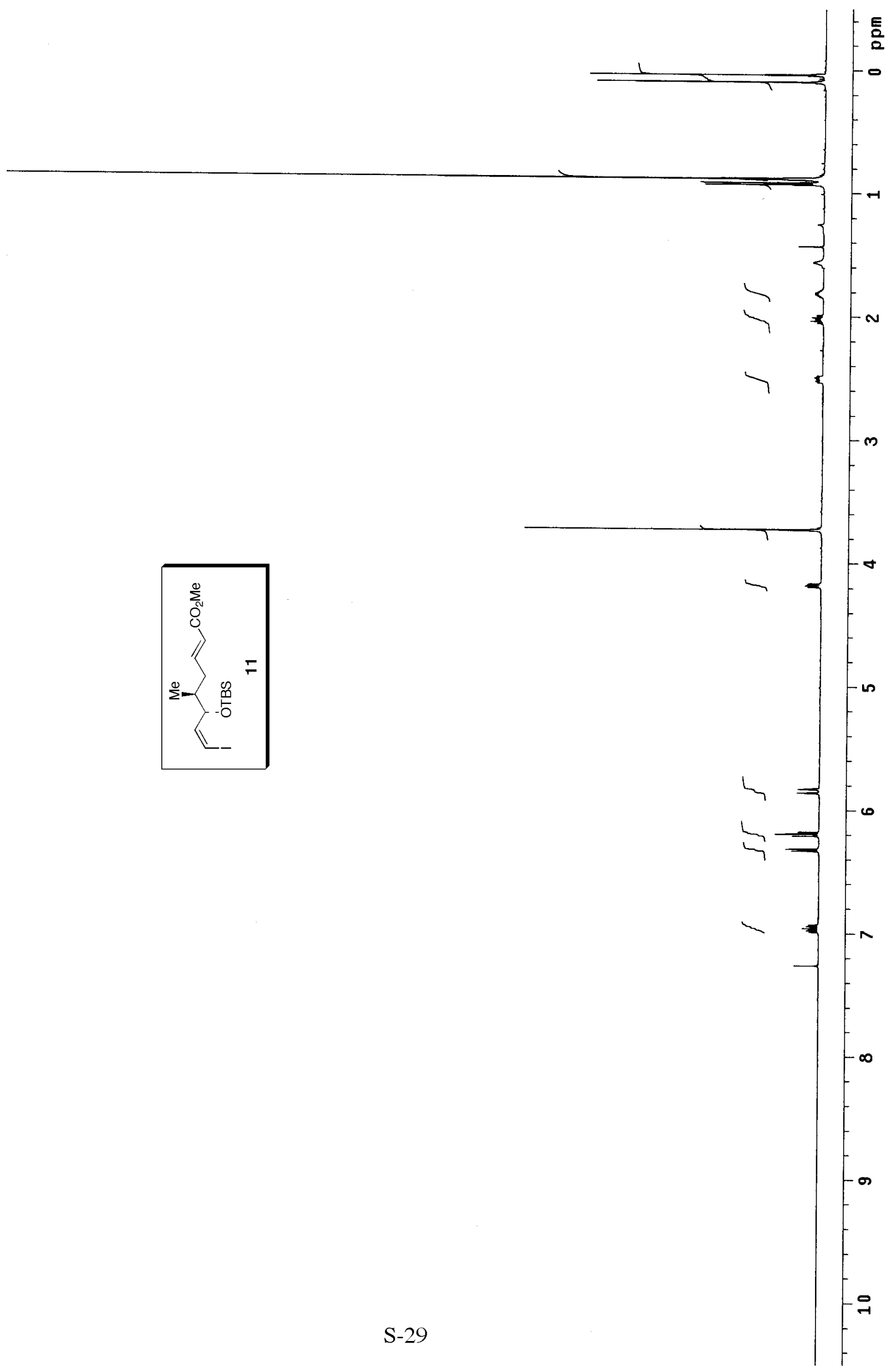




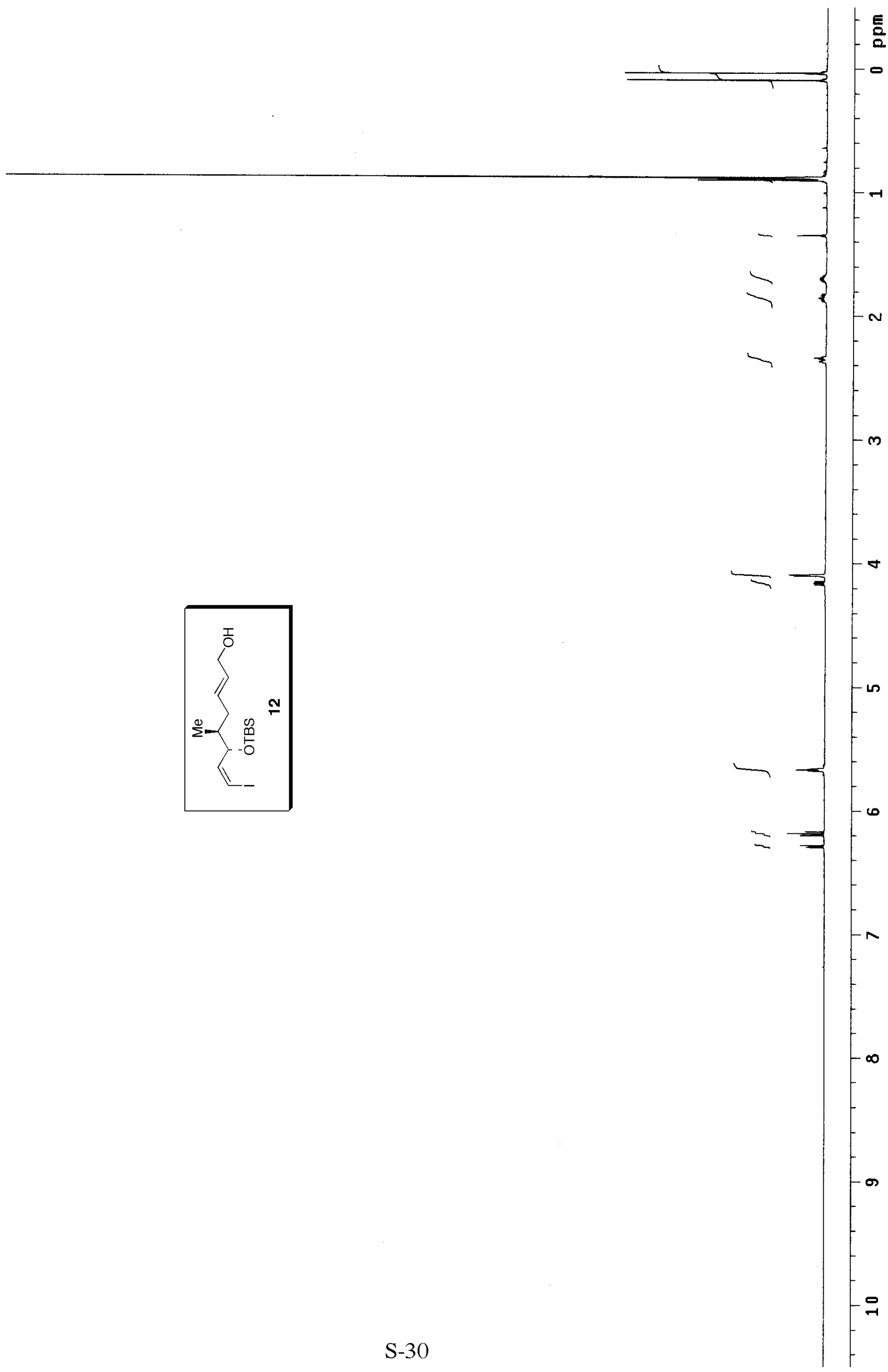




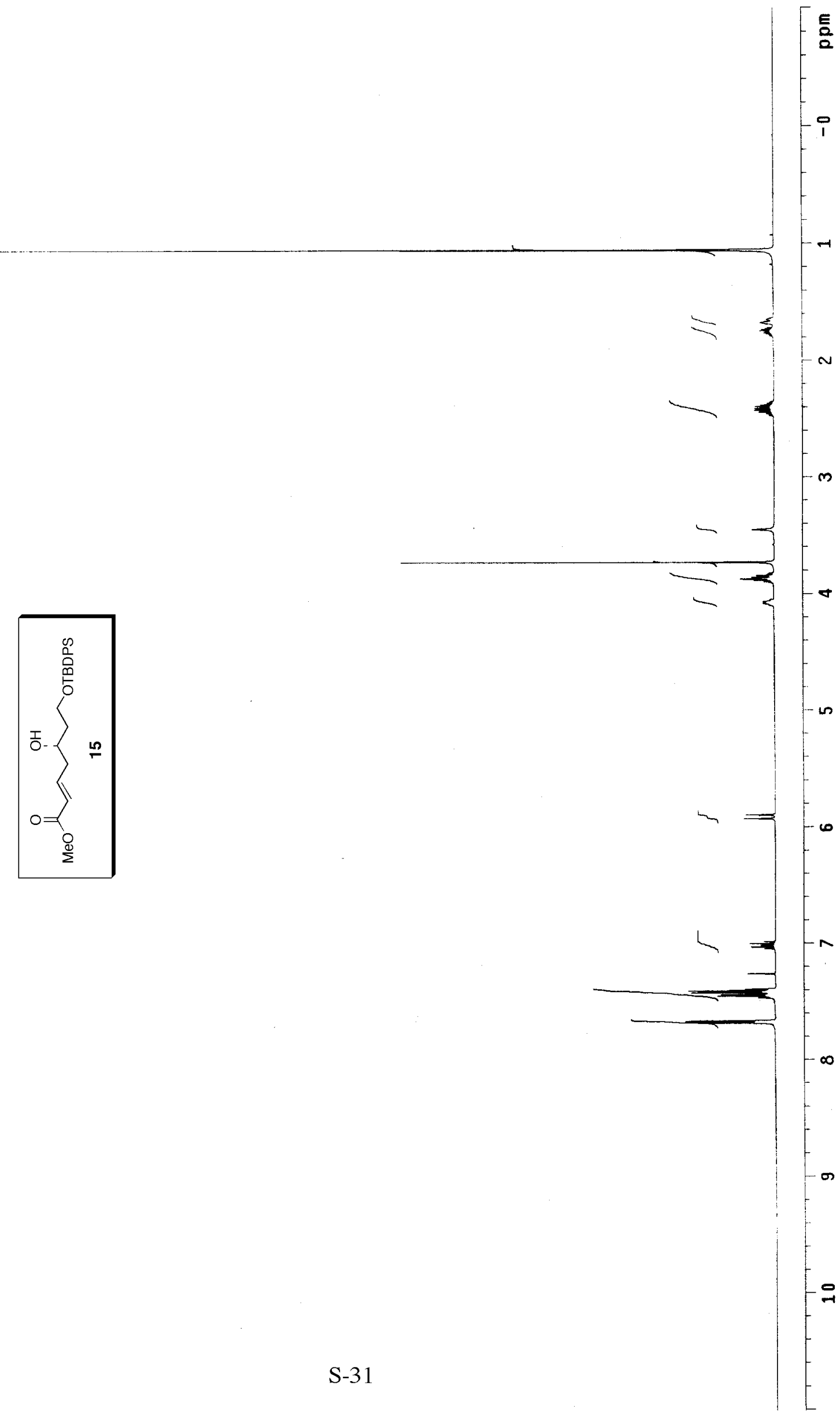




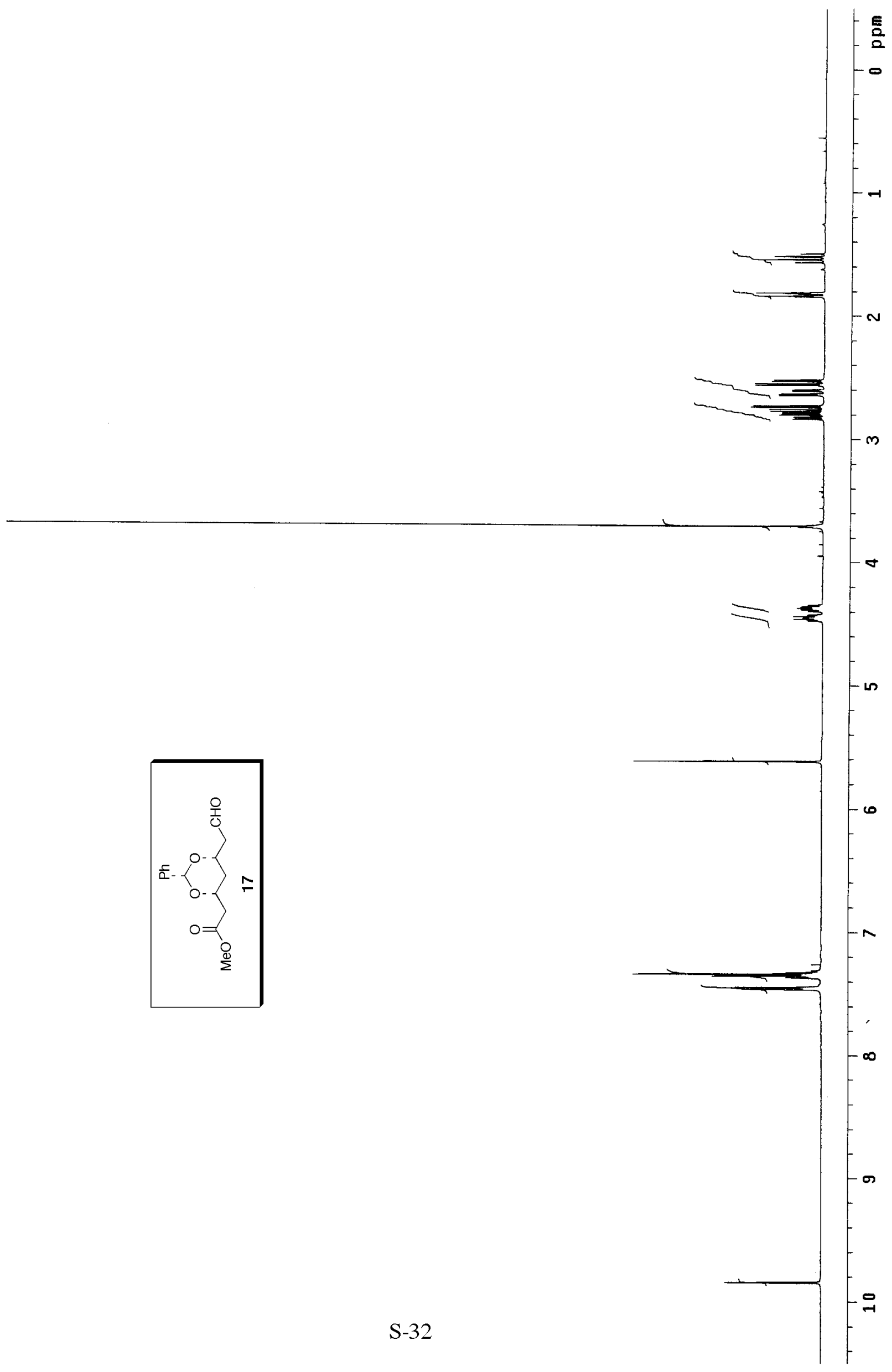




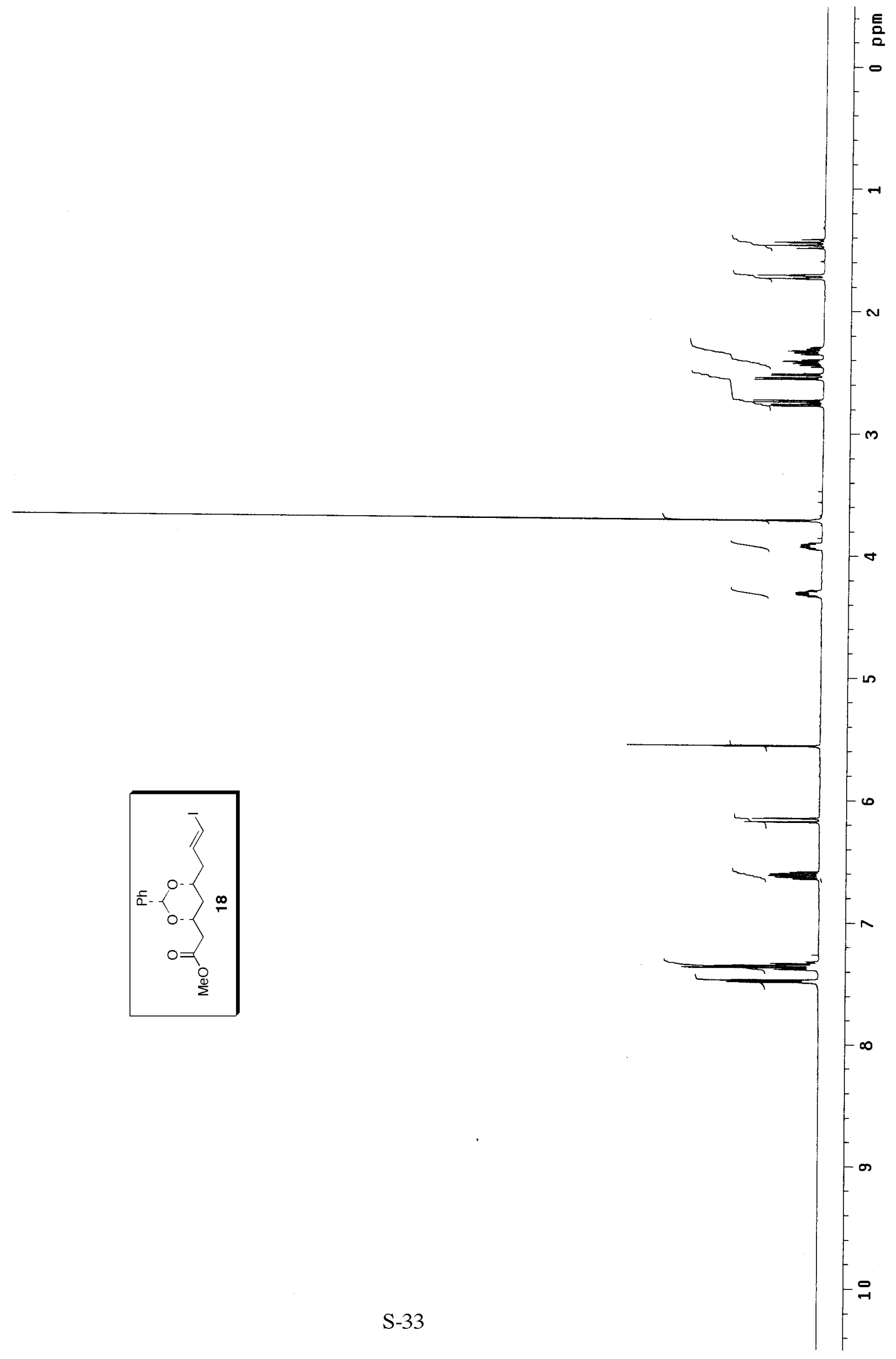




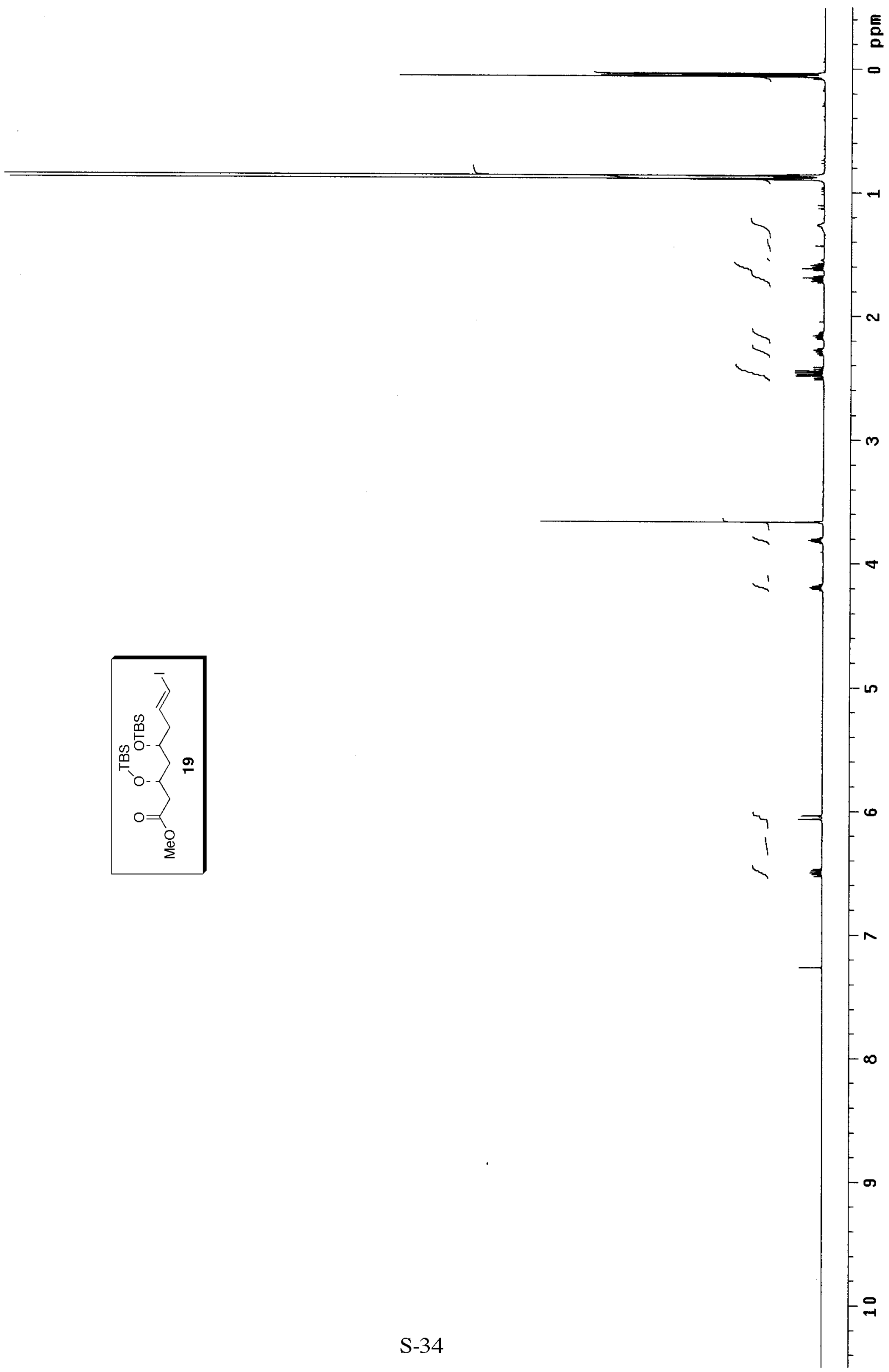




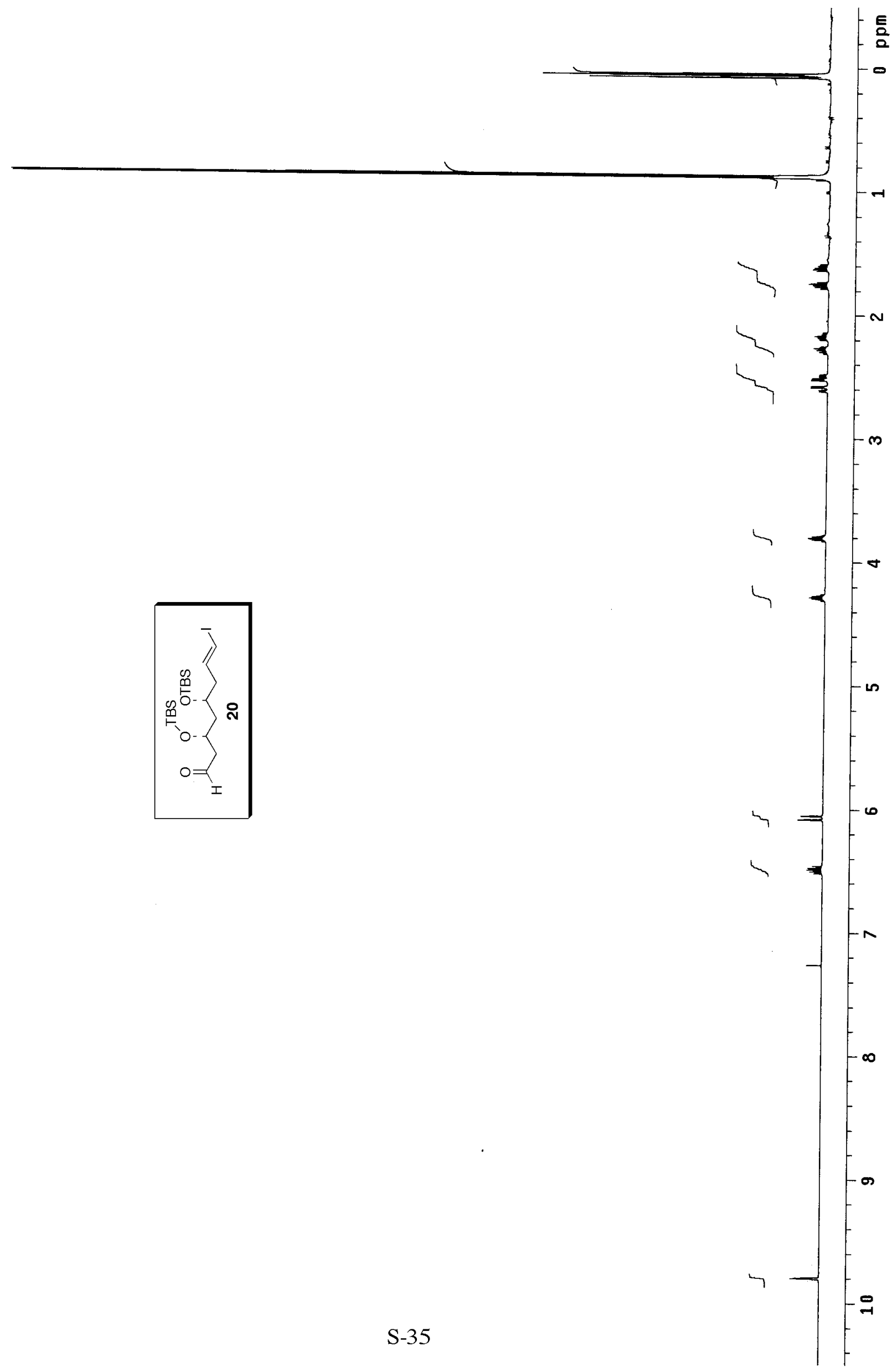




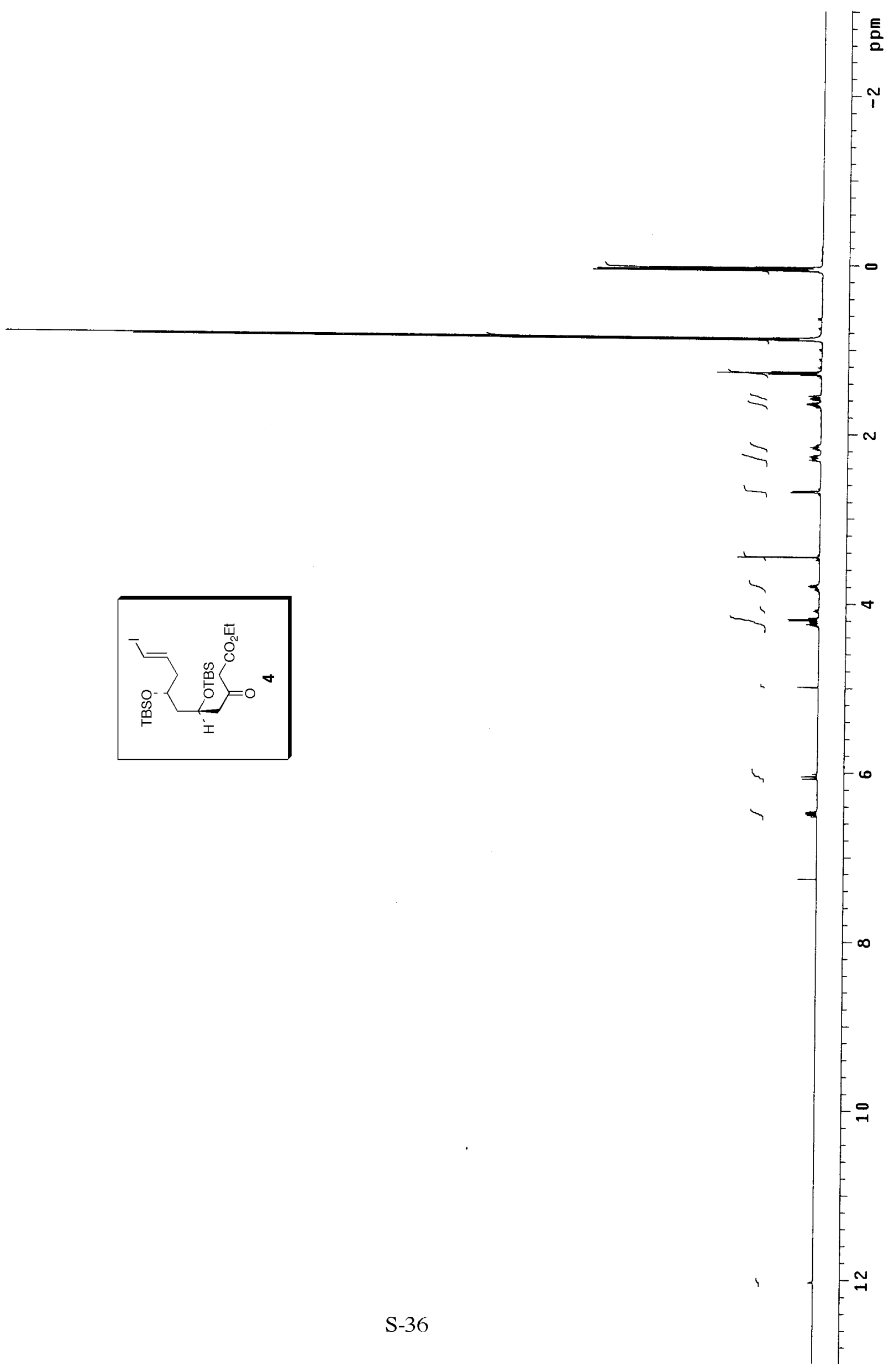




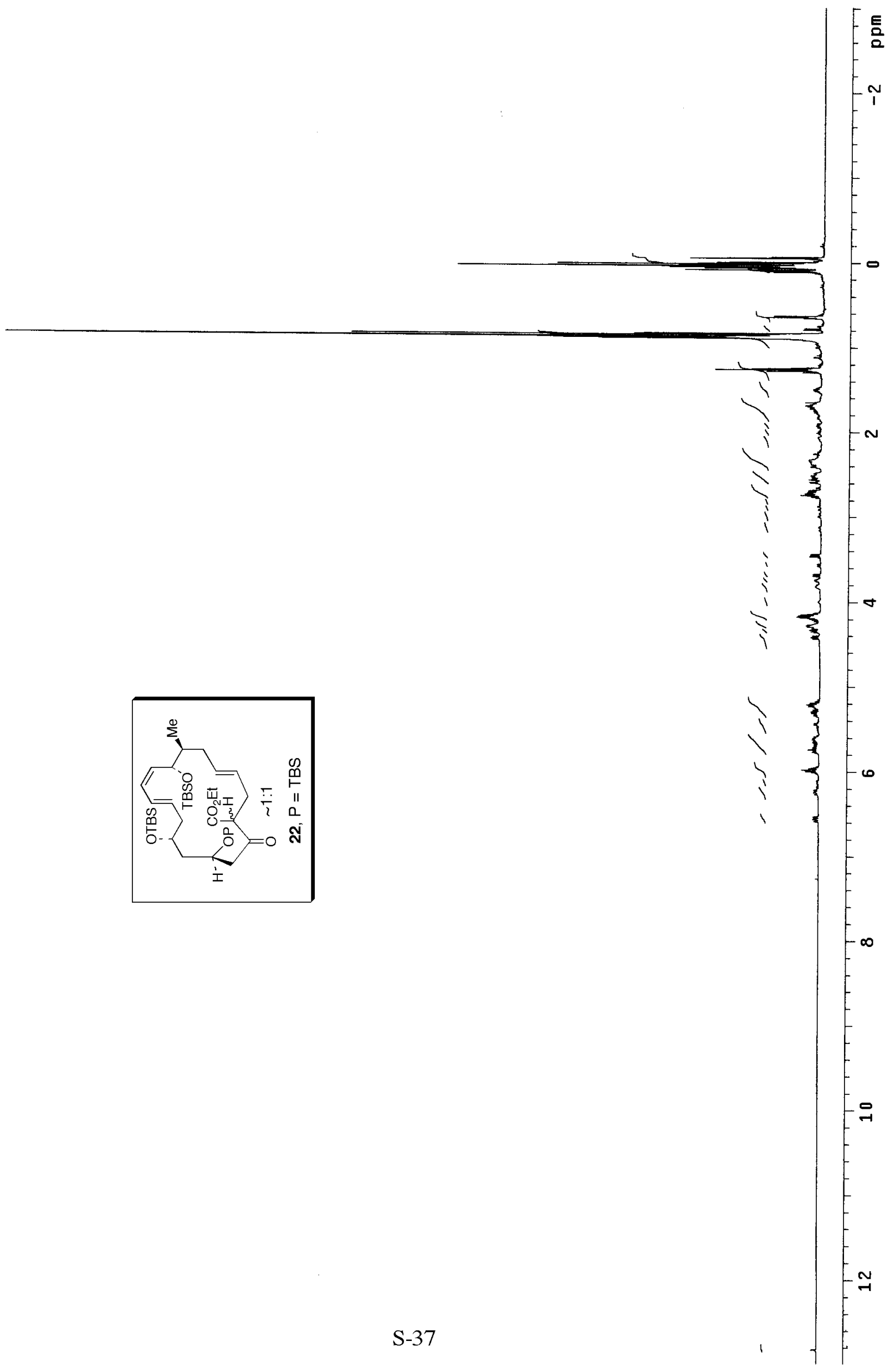




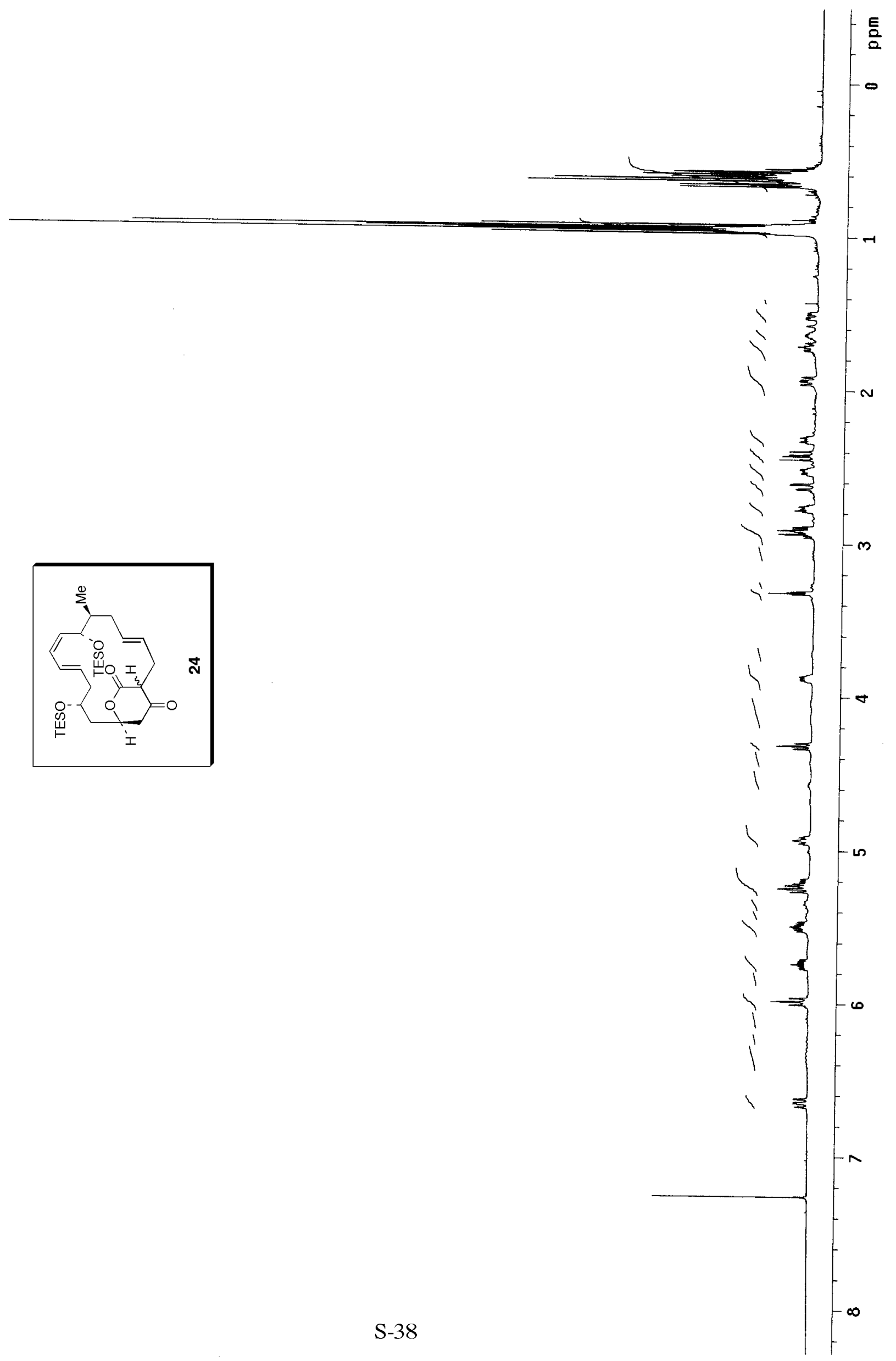




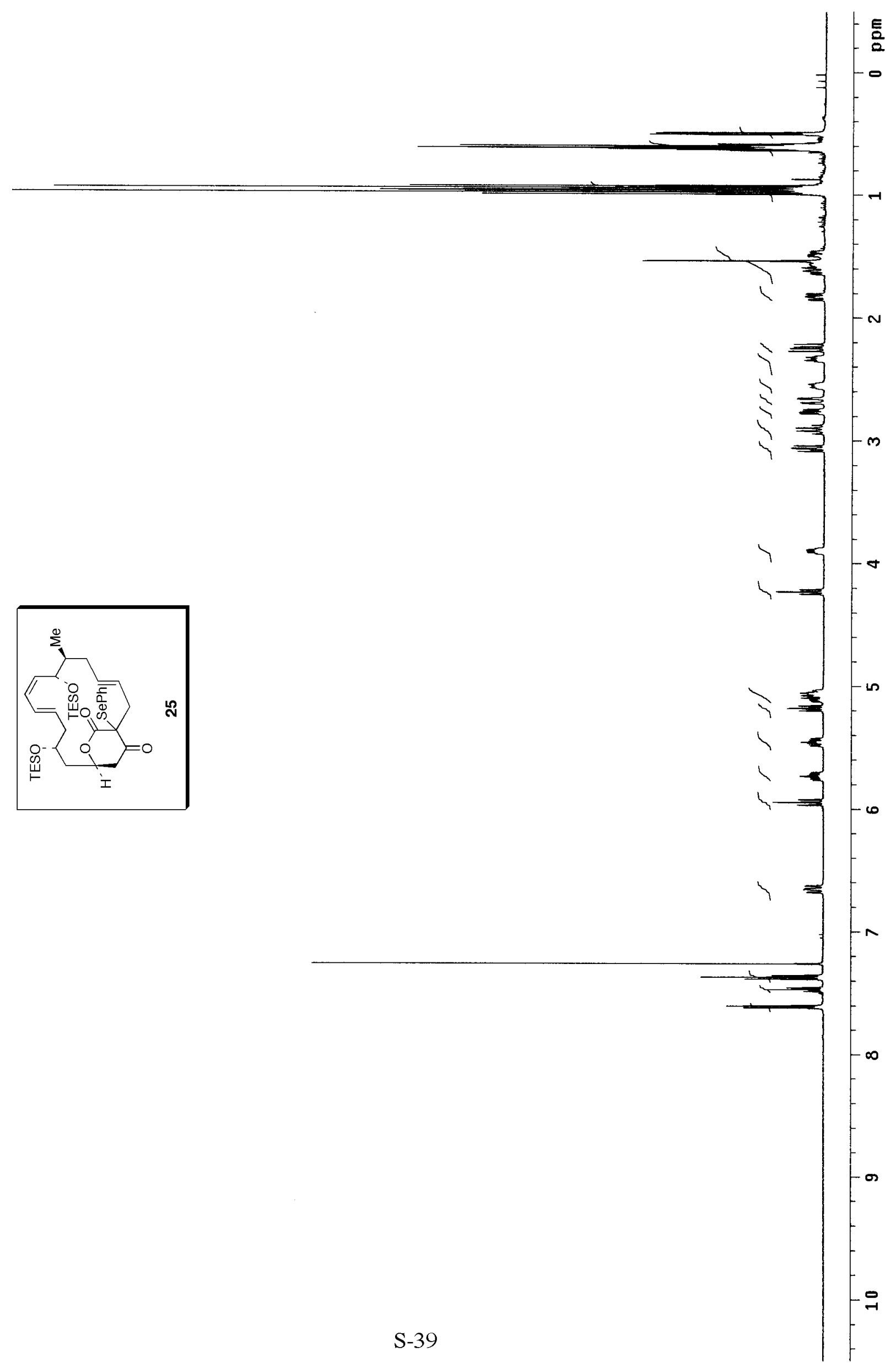




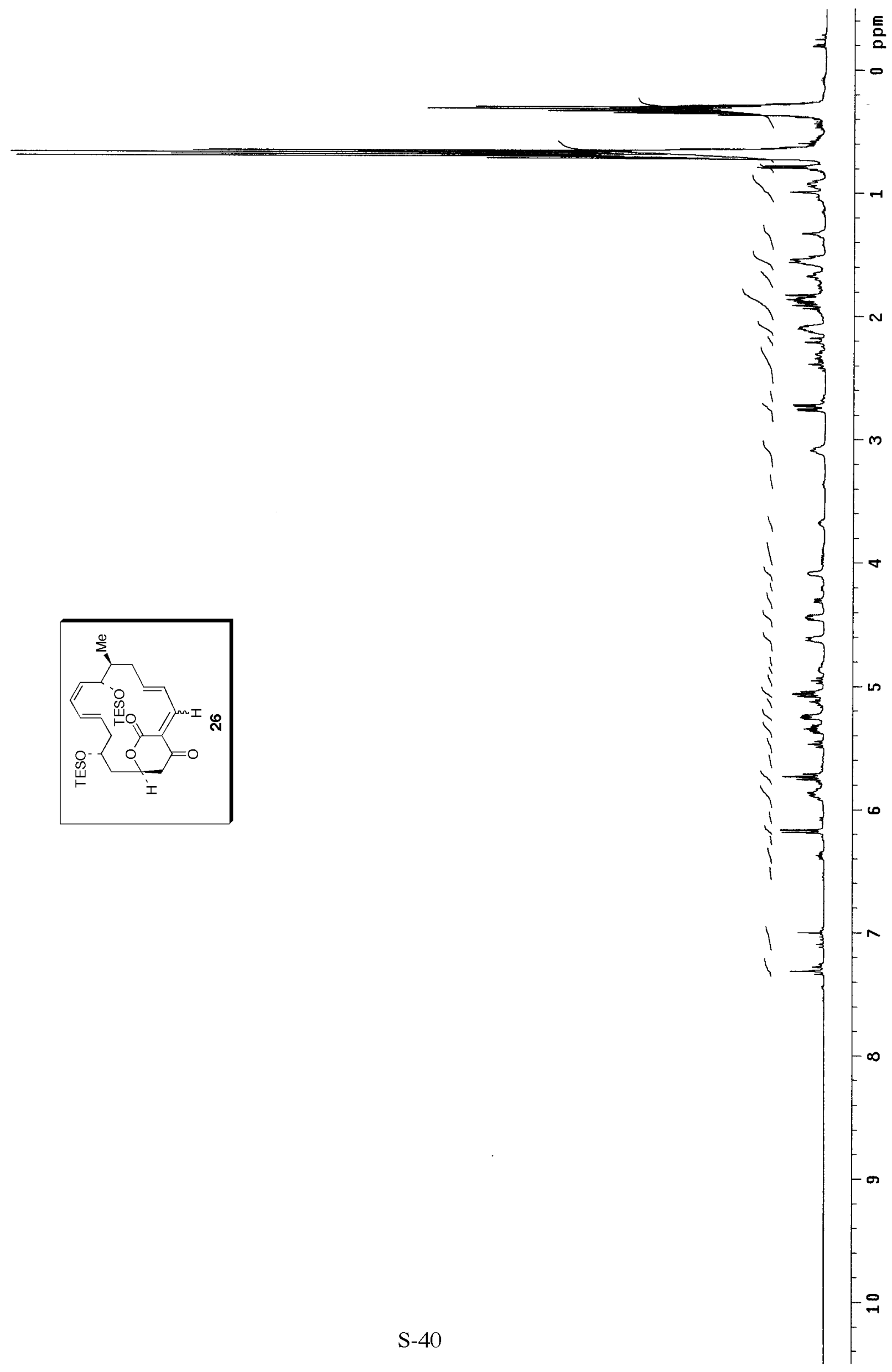




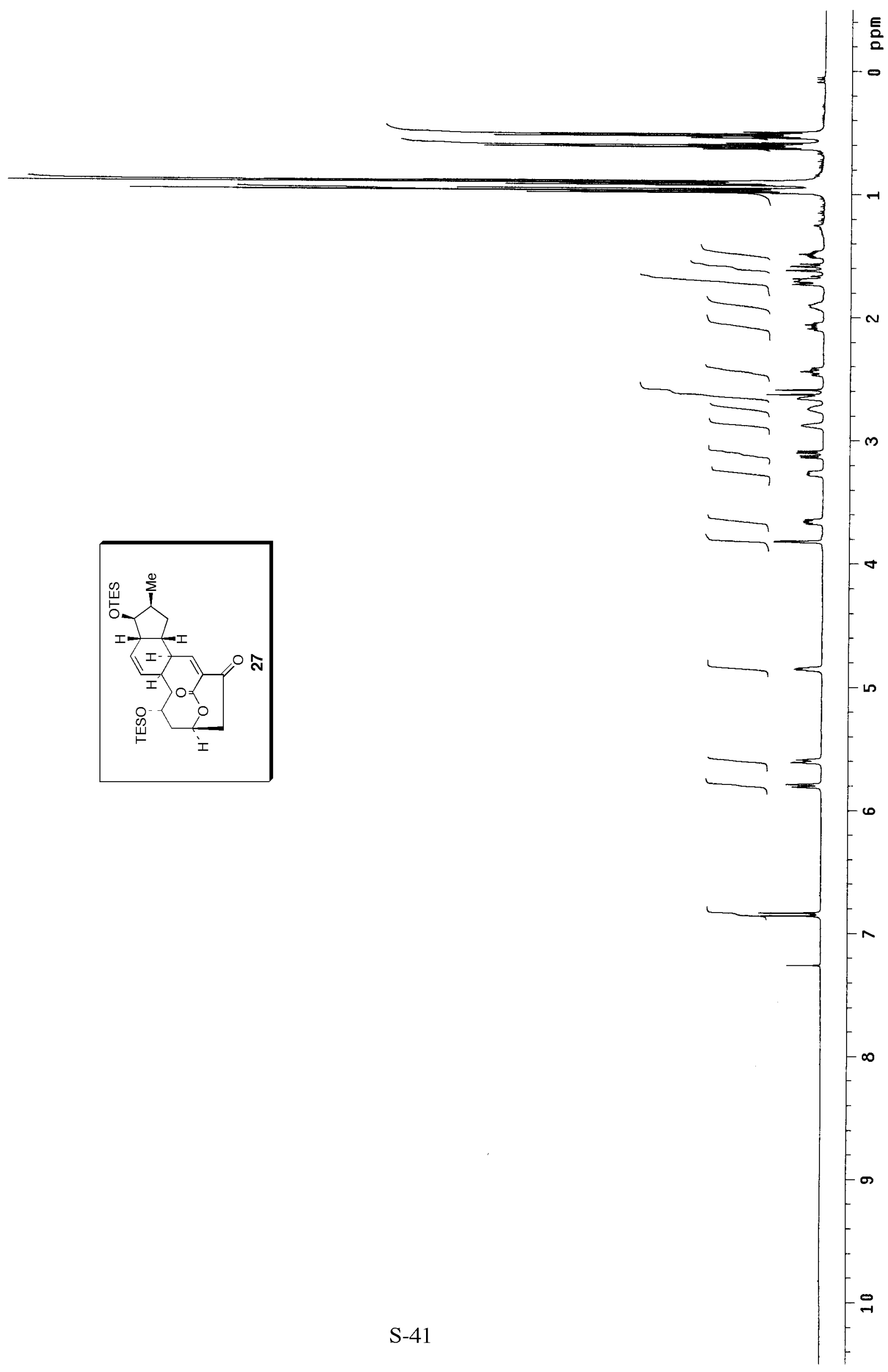




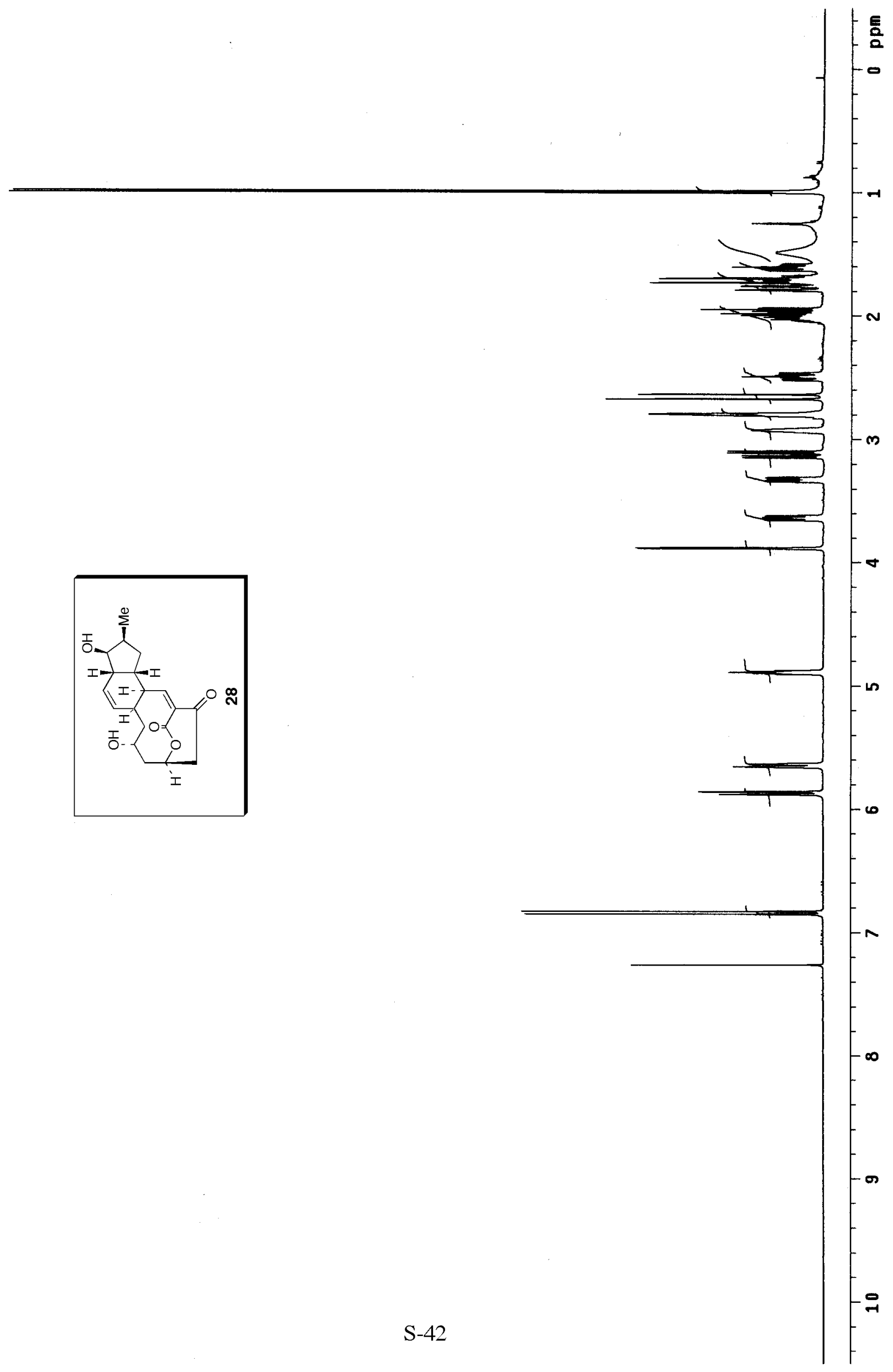




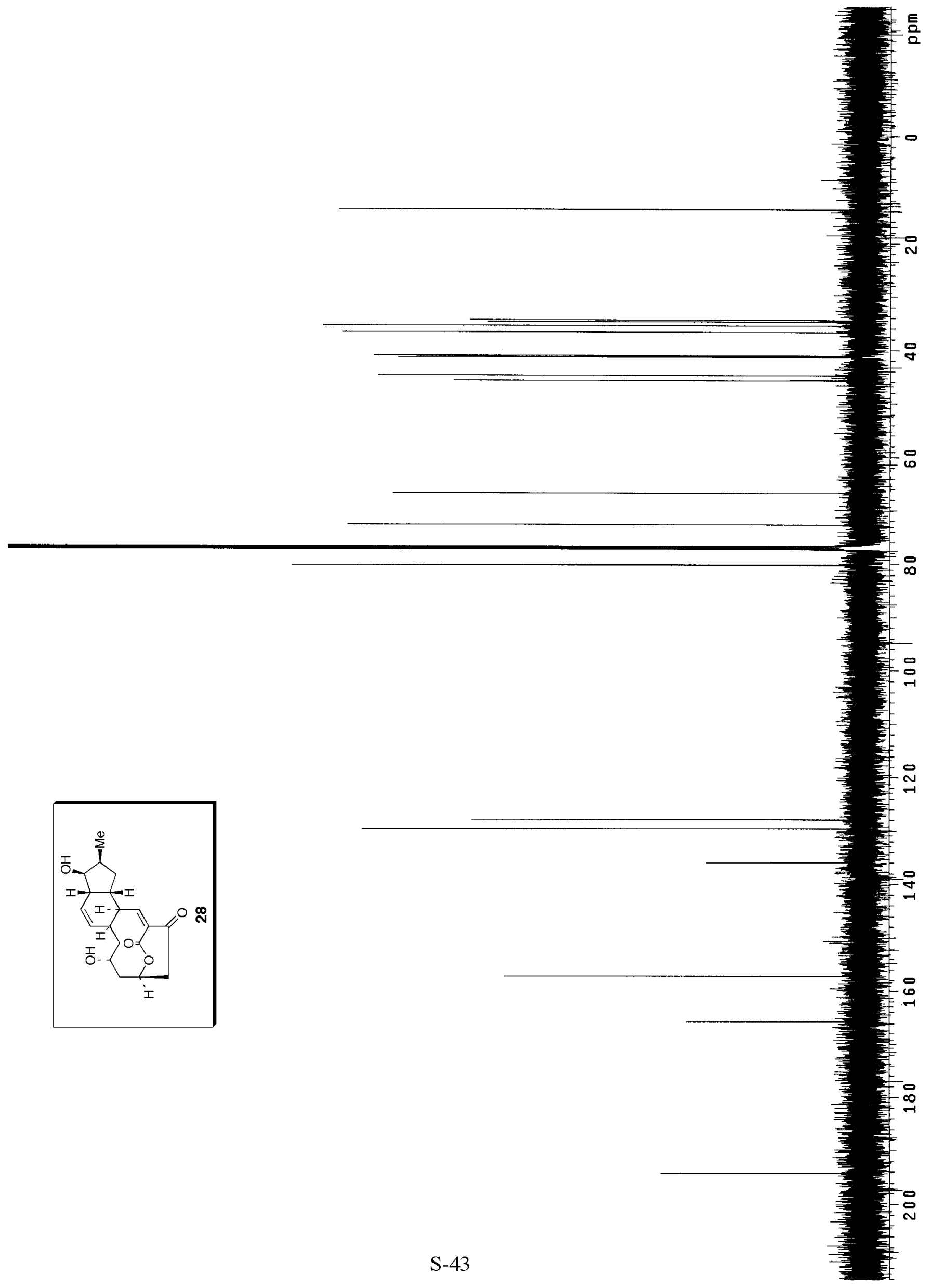




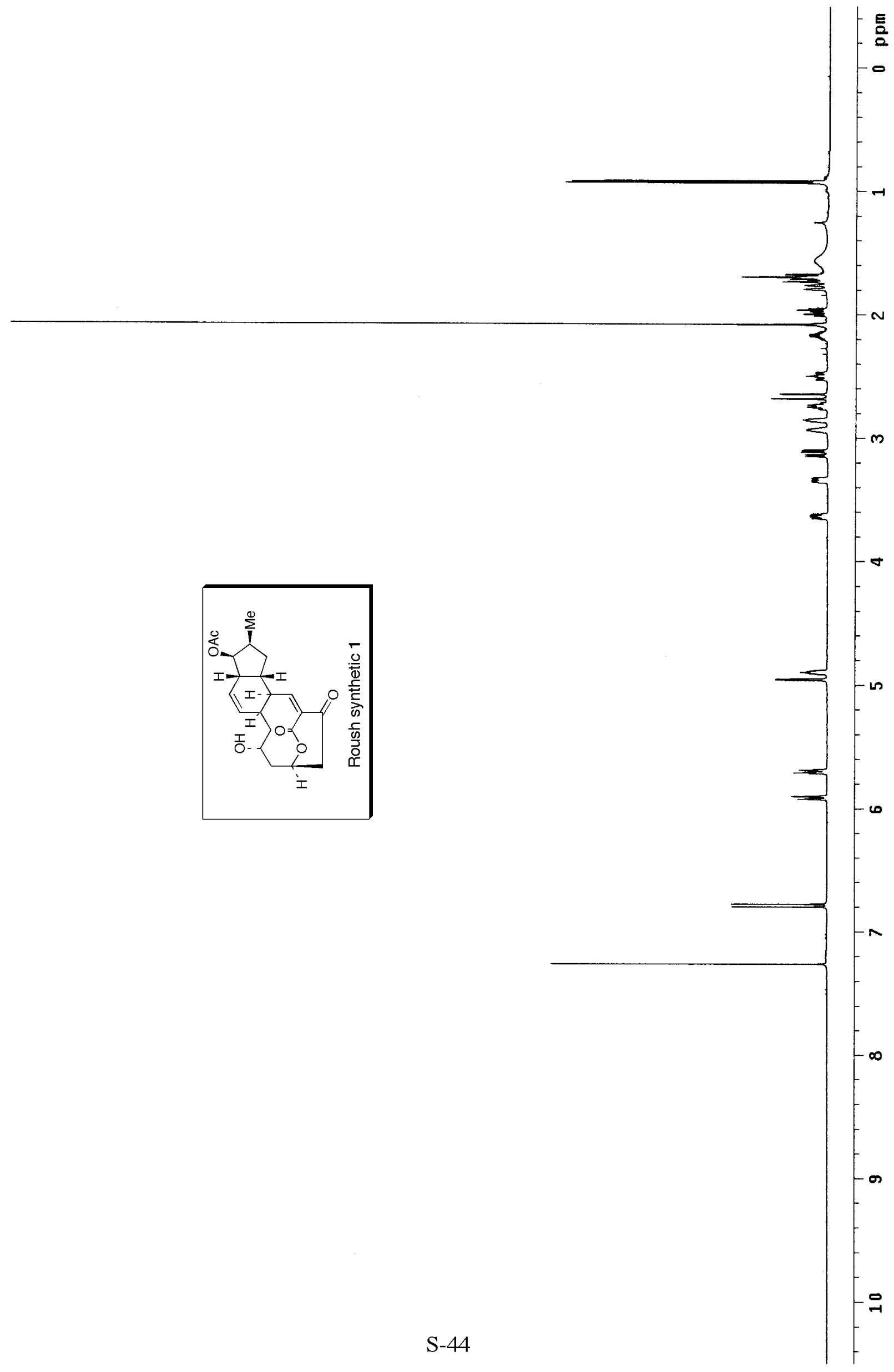




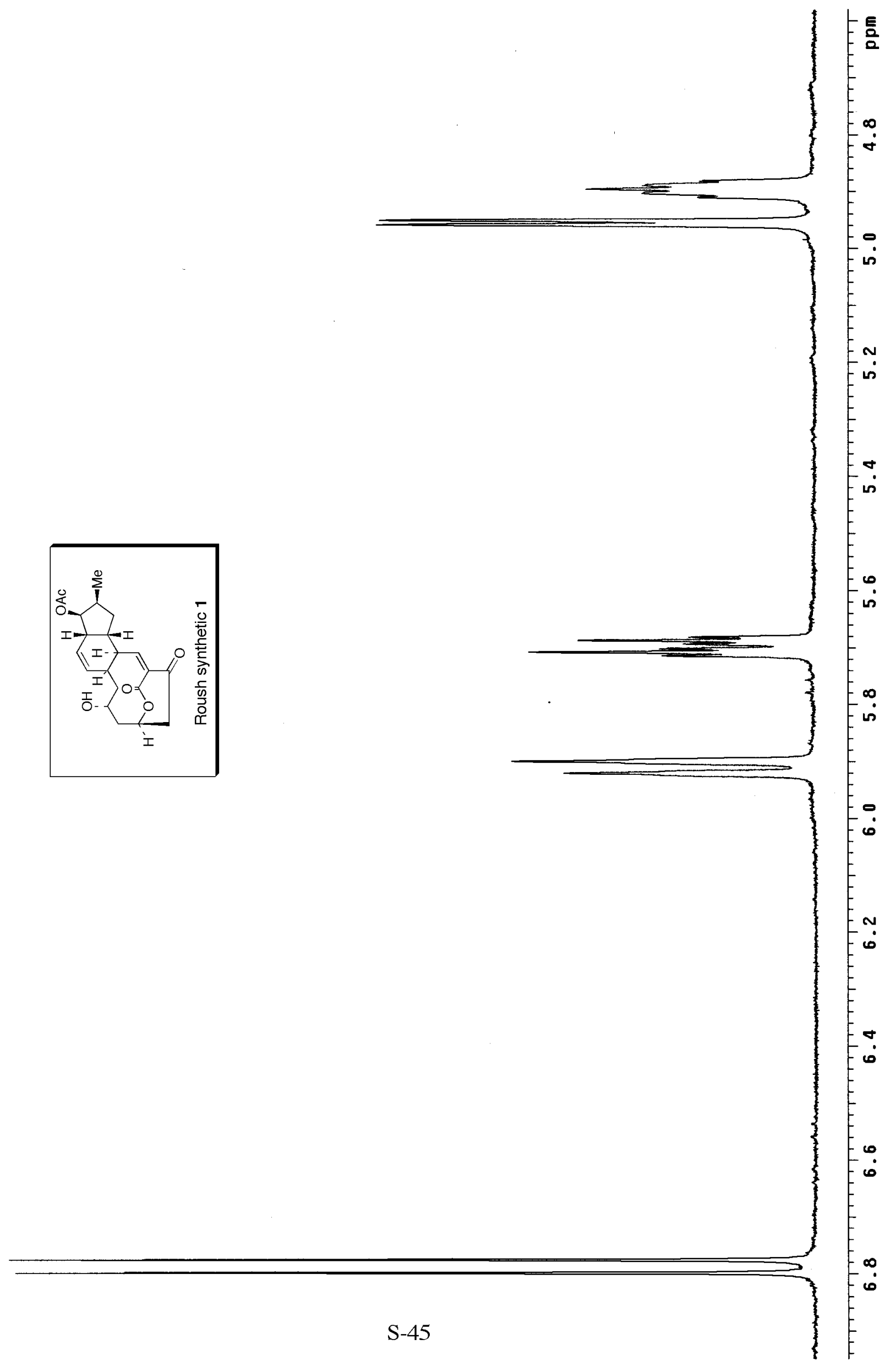




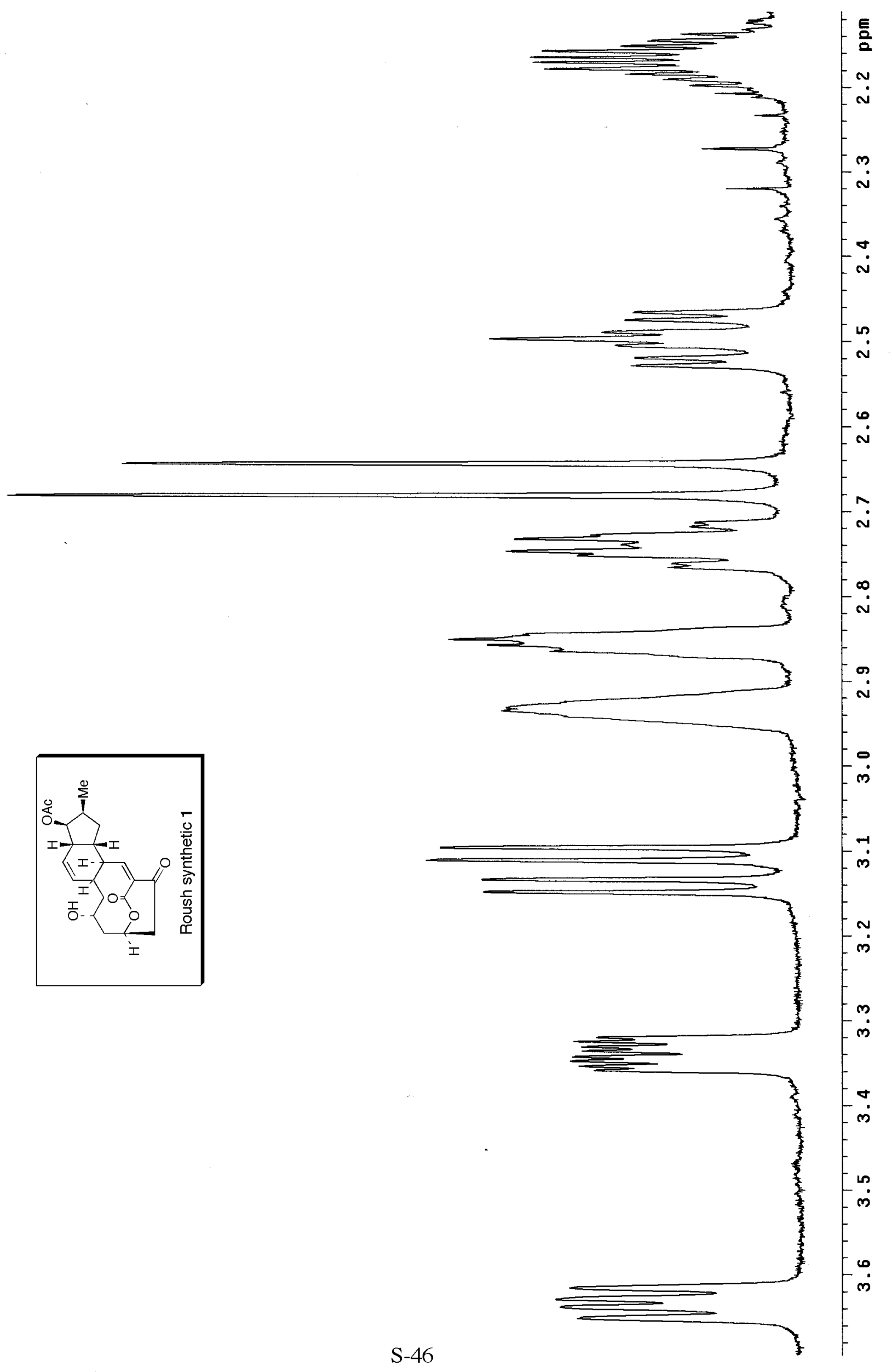




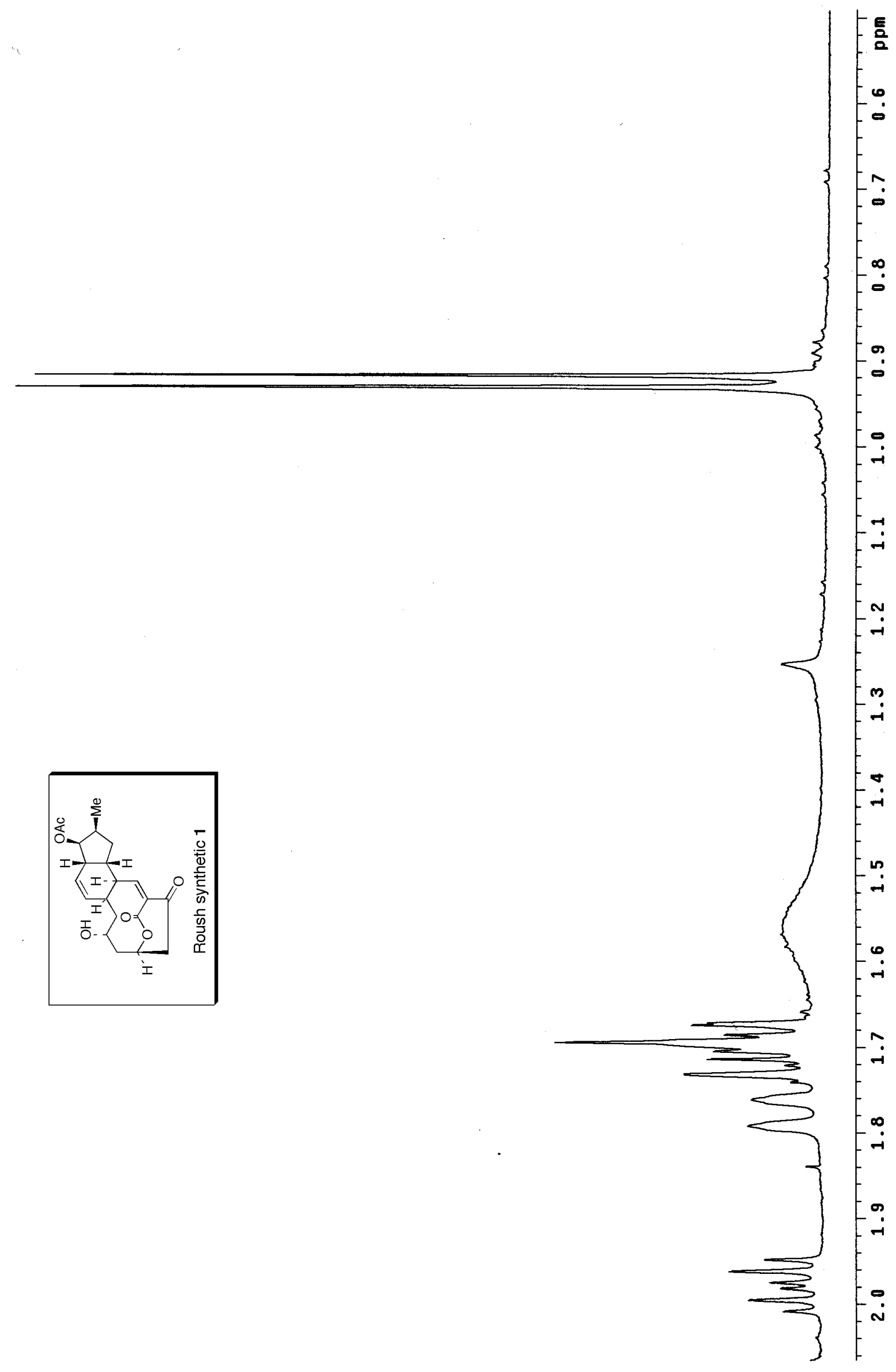




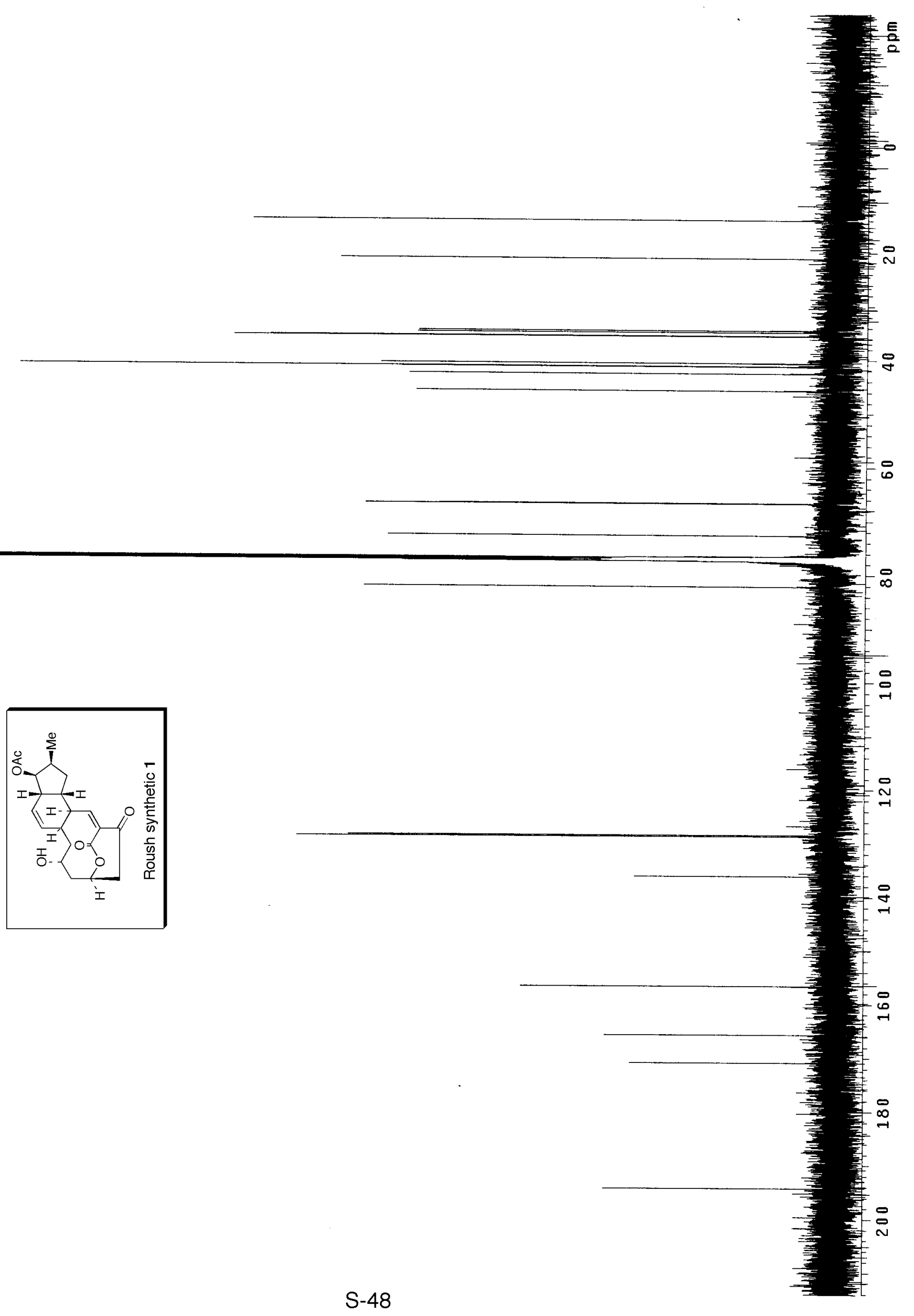




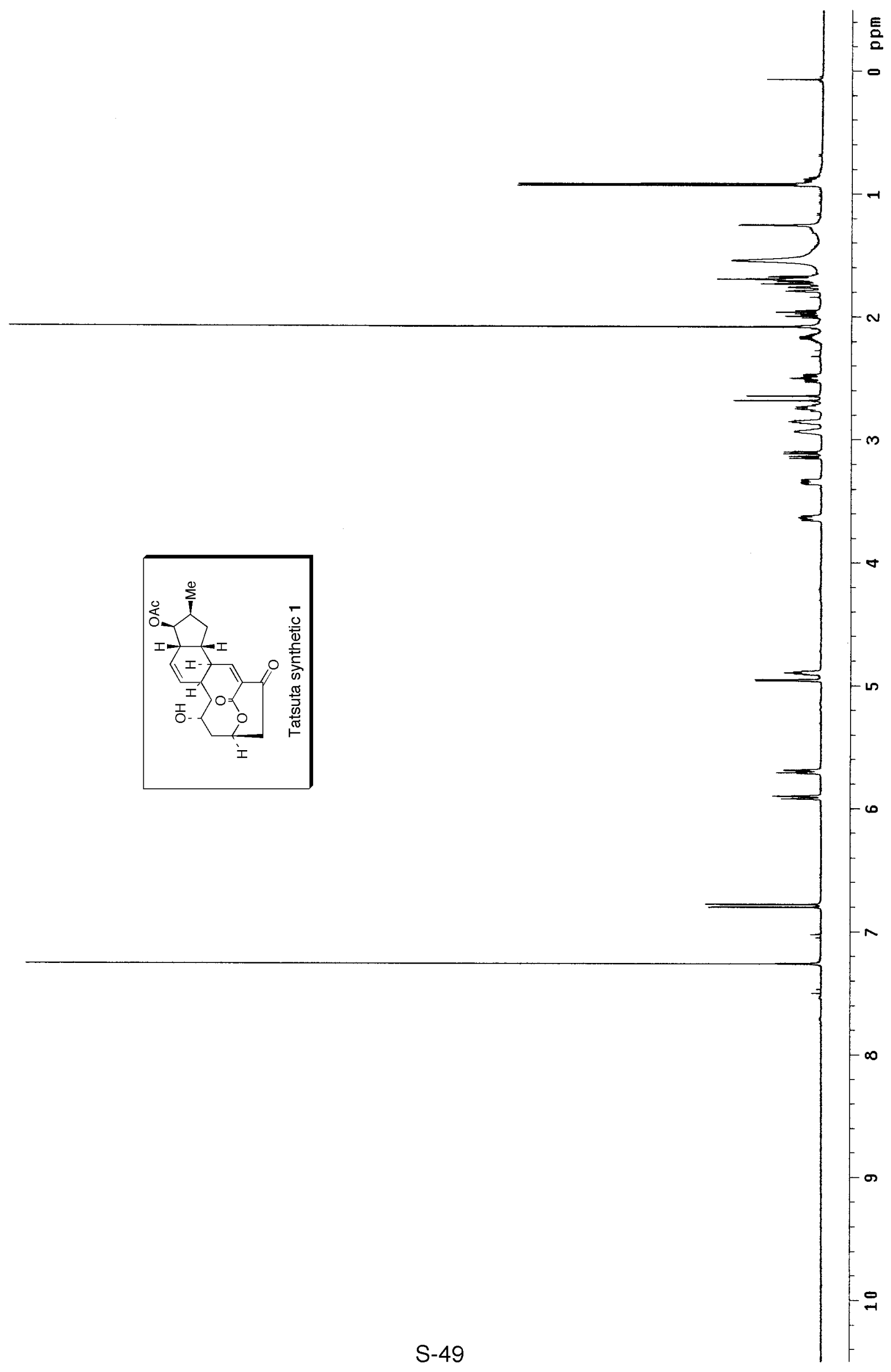




\section{Comparison of ${ }^{1} \mathrm{H}$ NMR Spectra of Cochleamycin A}

$\begin{array}{cl}\text { Signal } & \text { Natural Sample (lit.) } \\ & \\ \text { H1 } & 4.88(\mathrm{ddd}, \mathrm{J}=7.5,4.5,2.4) \\ \text { H5 } & 6.77(\mathrm{~d}, \mathrm{~J}=11.3) \\ \text { H6 } & 3.30 \text { (dd, } \mathrm{J}=11.3,5.6,2.4) \\ \text { H7 } & 2.72 \text { (ddd, } \mathrm{J}=10.0,7.0,7.0,2.4) \\ \text { H8 } & 1.68 \text { (overlap) } \\ & 1.70 \text { (overlap) } \\ \text { H9 } & 2.05 \text { (overlap) } \\ \text { H10 } & 4.94(\mathrm{~d}, \mathrm{~J}=3.8) \\ \text { H11 } & 2.84(\mathrm{~m}) \\ \text { H12 } & 5.63(\mathrm{ddd}, \mathrm{J}=10.0,3.0,3.0) \\ \text { H13 } & 5.91(\mathrm{ddd}, \mathrm{J}=10.0,2.4,2.4) \\ \text { H14 } & 2.92(\mathrm{~m}) \\ \text { H15 } & 1.69(\mathrm{overlap}) \\ & 1.97(\mathrm{ddd}, \mathrm{J}=16.8,6.8,6.8) \\ \text { H16 } & 3.62(\mathrm{ddd}, \mathrm{J}=16.8,6.8,2.4) \\ \text { H17 } & 1.78(\mathrm{ddd}, \mathrm{J}=15.5,2.4,2.4) \\ & 2.48(\mathrm{ddd}, \mathrm{J}=15.5,11.8,4.5) \\ \text { H18 } & 2.66(\mathrm{~d}, \mathrm{~J}=19.0) \\ & 3.11(\mathrm{dd}, \mathrm{J}=19.0,7.5) \\ \text { H20 } & 0.92(\mathrm{~d}, \mathrm{~J}=7.0) \\ \text { H22 (OAc) } & 2.08(\mathrm{~s})\end{array}$

$\begin{array}{ll}\text { Tatsuta (lit. })^{2} & \text { Roush } \\ & \\ 4.90(\mathrm{dddd}, \mathrm{J}=7.5,4.5,3.0,1.0) & 4.89(\mathrm{ddd}, \mathrm{J}=7.5,4.5,2.4) \\ 6.79(\mathrm{~d}, \mathrm{~J}=11.5) & 6.78(\mathrm{~d}, \mathrm{~J}=11.4) \\ 3.34(\mathrm{ddd}, \mathrm{J}=11.5,5.5,2.5) & 3.33(\mathrm{ddd}, \mathrm{J}=11.2,5.6,2.4) \\ 2.74(\mathrm{dddd}, \mathrm{J}=10.0,7.0,6.5,2.5) & 2.74(\text { app. } \mathrm{q} . \mathrm{J}=7.1) \\ 1.68(\mathrm{ddd}, \mathrm{J}=14.0,9.5,6.5) & 1.68-1.74(\mathrm{~m}) \\ 1.70(\mathrm{ddd}, \mathrm{J}=14.0,10.0,10.0) & 1.68-1.74(\mathrm{~m}) \\ 2.16(\mathrm{dddq}, \mathrm{J}=10.0,9.5,4.0,6.5) & 2.18-2.14(\mathrm{~m}) \\ 4.96(\mathrm{dd}, \mathrm{J}=4.0,0.0) & 4.95(\mathrm{~d}, \mathrm{~J}=3.9) \\ 2.83-2.87(\mathrm{~m}) & 2.85-2.86(\mathrm{~m}) \\ 5.70(\mathrm{ddd}, \mathrm{J}=10.0,3.0,3.0) & 5.69(\mathrm{dt}, \mathrm{J}=10.3,3.2) \\ 5.91(\mathrm{ddd}, \mathrm{J}=10.0,2.0,2.0) & 5.91(\mathrm{~d}, \mathrm{~J}=10.3) \\ 2.91-2.96(\mathrm{~m}) & 2.93(\mathrm{br} . \mathrm{s}) \\ 1.71(\mathrm{ddd}, \mathrm{J}=17.0,0.0,0.0) & 1.68-1.74(\mathrm{~m}) \\ 1.98(\mathrm{ddd}, \mathrm{I}=17.0,7.0,6.5) & 1.98(\mathrm{dt}, \mathrm{J}=16.8,6.8) \\ 3.63(\mathrm{dddd}, \mathrm{J}=11.5,6.5,1.5,0.0) & 3.63(\mathrm{dd}, \mathrm{J}=11.2,7.1) \\ 1.78(\mathrm{ddd}, \mathrm{J}=15.0,3.0,1.5) & 1.79(\mathrm{br} . \mathrm{d}=15.1) \\ 2.50(\mathrm{ddd}, \mathrm{J}=15.0,1.5,4.5,1.0) & 2.50(\mathrm{ddd}, \mathrm{J}=15.9,11.7,4.9 \\ 2.66(\mathrm{dd}, \mathrm{J}=19.0,1.0) & 2.66(\mathrm{~d}, \mathrm{~J}=18.8) \\ 3.12(\mathrm{ddd}, \mathrm{J}=19.0,7.5,1.0) & 3.12(\mathrm{dd}, \mathrm{J}=18.8,7.3) \\ 0.92(\mathrm{~d}, \mathrm{~J}=6.5) & 0.92(\mathrm{~d}, \mathrm{~J}=6.8) \\ 2.08(\mathrm{~s}) & 2.08(\mathrm{~s})\end{array}$

\section{Comparison of ${ }^{13} \mathrm{C}$ NMR Spectra of Cochleamycin A}

$\begin{array}{lll}\text { Carbon } & \text { Natural Sample (lit.) })^{1} & \text { Roush } \\ 1 & 72.8 & 72.7 \\ 3 & 165.7 & 165.6 \\ 4 & 136.1 & 136.1 \\ 5 & 154.0 & 156.6 \\ 6 & 40.6 & 40.7 \\ 7 & 35.6 & 35.6 \\ 8 & 34.9 & 34.9 \\ 9 & 35.5 & 35.5 \\ 10 & 82.2 & 82.1 \\ 11 & 42.5 & 42.5 \\ 12 & 128.6 & 128.6 \\ 13 & 128.6 & 128.4 \\ 14 & 34.5 & 34.9 \\ 15 & 41.1 & 41.2 \\ 16 & 66.5 & 66.7 \\ 17 & 45.6 & 45.7 \\ 18 & 41.1 & 41.2 \\ 19 & 194.2 & 194.2 \\ 20 & 13.9 & 14.0 \\ 21 & 170.9 & 170.8 \\ 22 & 21.1 & 21.2\end{array}$

${ }^{1}$ Shindo, K.; IIjima, H.; Kawai, H. J. Antibiot. 1996, 49, 244-247.

${ }^{2}$ Tatsuta, K.; Narazaki, F.; Kashiki, N.; Yamamoto, J.; Nakano, S. J. Antibiot. 2003, 56, 584-590. 